\title{
Effect of perforation size and substrate bag fruiting position on the morphology of fruiting bodies and clusters in Pleurotus ostreatus (Jacq.) P. Kumm
}

\author{
Iryna Bandura ${ }^{1}$, Omoanghe S. Isikhuemhen ${ }^{2 *}$, Alina Kulik ${ }^{1}$, Marina Serduk ${ }^{1}$, Olena Sucharenko ${ }^{1}$, Valentina Jukova ${ }^{1}$, \\ Viktoriia Koliadenko', Nona Gaprindashvili ${ }^{1}$ \\ ${ }^{1}$ Department of Food Technology, Hotel and Restaurant Business, Tavria State Agrotechnological University, 18 B. Khmelnytsky Avenue, Melitopol, Ukraine. \\ ${ }^{2}$ Department of Natural Resources and Environmental Design, North Carolina AT State University, Greensboro, NC 27411, USA.
}

\section{ARTICLE INFO}

Article history:

Received on: November 09, 2020

Accepted on: December 12, 2020

Available online: May 10, 2021

\section{Key words:}

Biological efficiency,

Fruiting body morphology,

Fruiting position,

Mushroom clusters size,

Pleurotus ostreatus,

Weight loss coefficient.

\begin{abstract}
Perforation or fruiting hole size on substrate bags control cluster sizes and morphology in exotic mushroom cultivation. The effect of three different perforation sizes on substrate bags (factor A: 50, 100, and $150 \mathrm{~mm}$ ) and their positioning on the shelves (factor B: Horizontal, vertical, and slant) on the crop and various morphological characteristics in Pleurotus ostreatus was studied. Microclimatic conditions for fruiting were $16 \pm 1^{\circ} \mathrm{C}, 87 \pm 3 \% \mathrm{RH}$; $230 \pm 42$ lux illumination. The formula for calculating area of ellipse was modified and used for the area of mushroom cap. Results indicated that the total fruit body yield and biological efficiency (BE) in the bags set in horizontal position were $10 \%$ lower than other treatments. The effect of perforation size on mushroom cluster sizes was more on the substrate blocks in the horizontal position. There was a linear correlation between perforation size and fruiting body cluster sizes. Results suggest that the $50 \mathrm{~mm}$ perforation on bags in vertical and slant positions gave fruiting body clusters sizes $186-196 \mathrm{~mm}$ width and $122-154 \mathrm{~mm}$ height, with $92.36 \pm 6.48 \% \mathrm{BE}$. The cluster size indicated is the best fit for standard packaging containers used in commercial oyster mushroom production in Ukraine.
\end{abstract}

\section{INTRODUCTION}

The demand for exotic mushrooms is increasing every day due to their nutritional and medicinal values. The combined production of Pleurotus spp. ranks second after the Agaricus bisporus, primarily because of the availability of highly efficient cultivation technology, the nutritional and medicinal properties [1,2], and various other uses [3-5].

In 2004, fresh oyster mushroom consumption per capita was $2.72 \mathrm{~kg}$; by 2018 , it has reduced to $1.63 \mathrm{~kg}$ per capita, and the number of producers did not change; large quantities of mushrooms are now pickled. One of the reasons for the drop in per capita consumption of fresh oyster mushrooms is consumers are now more selective about the quality, appearance, and packaging of fresh mushrooms. Therefore, it has become necessary to look at consumer appeals to improve marketing and sales locally, and post-harvest processing acceptable for export. Consumers like both fresh and canned oyster mushrooms. However, most producers sell fresh mushrooms; therefore, size, appearance, and ,packaging have become very important.

*Corresponding Author:

Omoanghe S. Isikhuemhen, Department of Natural Resources and

Environmental Design, North Carolina AT State University, Greensboro, NC

27411,USA. E-mail: omon@ncat.edu
Across Europe, consumer preferences are dictating the need to produce mushrooms with high organoleptic properties such as rich color, delicate texture, and optimal size of fruiting bodies. According to the latest estimates of Champinter, a mushroom marketer in Spain, $300 \mathrm{~g}$ packets of peeled mushrooms, which is enough for two servings of a delicious meal, is most preferred. In the case of oyster specifically, buyers prefer packages containing a collection of individual fruiting bodies, although oyster mushroom keeps better in sprouts clumps [6]. Humidity, lightning, and air composition are factors that can affect the size and quality of mushrooms, and they are continually being studied by scientists [7]. It has been shown that substrate blocks with a fruiting hole diameter of $90 \mathrm{~mm}$ resulted in the highest number of fruit bodies and overall biological efficiency (BE) [8]. Zireva et al. [9] reported the effect of substrate size and their location in the growing chamber on mushroom fruiting body yield. However, there are limited studies and reports on the effect of cultivation conditions (substrate bag position in the fruiting room, number of holes on substrate bags, size of each hole, etc.) on yield, BE, and organoleptic properties. We studied the effect of perforation size on substrate bags and the fruiting position of the bags on the morphology of fruiting bodies and clusters characteristics of Pleurotus ostreatus in a commercial production setting in Ukraine. 


\section{MATERIALS AND METHODS}

\subsection{Spawn Preparation}

P. ostreatus (strain $2301 \mathrm{IBK}$ ) used is from the culture collection of edible mushrooms at the Institute of Botany, Ukraine [10]. The culture was maintained on nutrient media (maltdextrose $-20 \mathrm{~g}$, yeast extract $-2 \mathrm{~g}$, and agar-agar $-20 \mathrm{~g}$, in $1 \mathrm{~L} \mathrm{ddH} 2 \mathrm{O}$ ) and stored at $1-2^{\circ} \mathrm{C}$ [11]. Spawn was made with barley, wheat, rape, flax, and chalk $\left(\mathrm{CaCO}_{3}\right)$ combined in the ratio 60:30:8:1:1. Pre-cooked barley and wheat, and pre-soaked rapeseeds, flax, and chalk, were mixed and loaded into polypropylene bags of size $(580 \mathrm{~mm} \times 490 \mathrm{~mm})$, PP75/BEU6/X47-57 (from Sac02, Belgium) and sterilized at $128^{\circ} \mathrm{C}, 24$ PSI for $180 \mathrm{~min}$. Upon cooling, the sterile grain mixture was inoculated with mother spawn $(0.5 \% \mathrm{w} / \mathrm{w})$, sealed and incubated at $24 \pm 1^{\circ} \mathrm{C}$ for 8 days before thorough mixing to allow the achieve uniform colonization of the spawn materials. The spawn was ready after $11 \pm 1$ days and stored in a refrigerator $\left(2 \pm 1^{\circ} \mathrm{C}\right)$ until use.

\subsection{Substrate Preparation}

The substrate used for cultivation contained straw substrate and sunflower husk (ratio 1:3), humidity $=72 \% ; \mathrm{pH}=8.02$; carbon to nitrogen ratio $(\mathrm{C}: \mathrm{N})=69: 1$, was pasteurized using a three-step process: Pre-fermentation, pasteurization, and fermentation [12]. During the pre-fermentation process, the combined raw substrate materials were loaded into the pasteurization chamber $\left(\right.$ volume $\left.=45 \mathrm{~m}^{3}\right)$, hydrated to attain $72-74 \%$ moisture content, and maintained at $30-35{ }^{\circ} \mathrm{C}$ for 24 $36 \mathrm{~h}$. In the pasteurization step, steam was injected into the chamber to raise the temperature to $70-75^{\circ} \mathrm{C}$ and maintained for $12 \mathrm{~h}$; then, the temperature in the chamber was reduced to $50-55^{\circ} \mathrm{C}$ over $24 \mathrm{~h}$. Fast cooling with fresh air passed through an F-filter into the chamber was done to obtain ready to use substrate at $25-28^{\circ} \mathrm{C}$ [13].

A partially mechanized process involving a vibrating table, which thoroughly mixes the spawn with the substrate, was used to add spawn $(3.5 \% \mathrm{w} / \mathrm{w})$ to the substrate bags [14]. The substrate and spawn complex was loaded in $350 \mathrm{~mm} \times 900 \mathrm{~mm}$ polyethylene bags with a film thickness of $70 \mu \mathrm{m}$. Each substrate bag had a diameter$220 \pm 20 \mathrm{~mm}$, height $-750 \pm 50 \mathrm{~mm}$, and weight $-12.43 \pm 0.23 \mathrm{~kg}$.

\subsection{Growing Conditions}

The incubation of the substrate and fruiting process was done in the same room. The room temperature during the spawn-run (incubation) period was set at $20 \pm 2{ }^{\circ} \mathrm{C}$ (which allowed the temperature in the center of the bag block to be $26 \pm 2^{\circ} \mathrm{C}$ ) and relative humidity of $75 \pm 3 \%$. For fruiting body induction, the temperature in the room was gradually reduced to $16 \pm 1^{\circ} \mathrm{C}$ over $48 \mathrm{~h}$ by ventilation system with the addition of fresh air and reduced $\mathrm{CO}_{2}$ concentration in the chamber from $3200 \pm 100$ to $1050 \pm 100 \mathrm{ppm}$, the relative humidity increased to $87 \pm 3 \%$, and illumination increased from $50 \pm 12$ (daylight) to $230 \pm 42$ lux. These microclimate conditions in the growing room were maintained through fruiting body development to harvest.

\subsection{Data Collection}

The bags with substrates were placed on the shelves in a growing chamber in a complete randomized block design, based on the position of the substrate bag: $1=$ Horizontal; 2 = Vertical, and $3=$ Slant (factor A). There were 30 bags in each fruiting position, which were further divided into three groups of 10 bags, each representing 50 or 100 or $150 \mathrm{~mm}$ perforations (Factor B) and perforated. The surface on each bag perforated was an average of $0.2 \%$ of the total bag surface area. There were 12 holes on the bags with $50 \mathrm{~mm}$, six holes with 100 $\mathrm{mm}$, and four holes with $150 \mathrm{~mm}$ incisions on the substrate bags. The perforations were staggered at distances of $100-150 \mathrm{~mm}$ apart on the front surface of each bag. After harvest, 25 randomly selected fruiting body clusters per treatment were analyzed for width, height, weight, and the number of individual fruiting bodies per cluster. The selected fruiting body clusters were picked apart, and 100 individual fruiting bodies were randomly selected per treatment for analysis. The weight of the individual fruiting body (intact fruiting body with cap and stipe), cap weight, width (diameter), and length (the distance from the end of stipe to the opposite end of mushrooms cap), stipe length, and diameter were determined [Figure 1].

\subsection{Data Analyses}

The coefficient of cap asymmetry was calculated as the ratio of width to length; it is equal to one when a fruiting body cap is round. The elongated leaf-shaped cap of the fruiting body found in oyster mushrooms had a coefficient below one. Furthermore, the coefficient of weight loss (CWL) when the stipe is separated from the fruiting body was calculated because some markets prefer "capsonly" fruiting bodies for sale. The coefficient was determined by the ratio of the cap's weight to the mass of the whole fruiting body. $P$. ostreatus fruiting body cap usually has the shape of an ellipse. Therefore, the formula $\mathrm{A}=\pi^{*} 1 / 2 \mathrm{x} * 1 / 2 \mathrm{y}$ or $\pi^{*} 1 / 4 \mathrm{xy}$ was used to calculate the area of the mushroom cap, where $y$ is the distance from the end of the stipe to the opposite end of the mushroom cap and $\mathrm{x}$
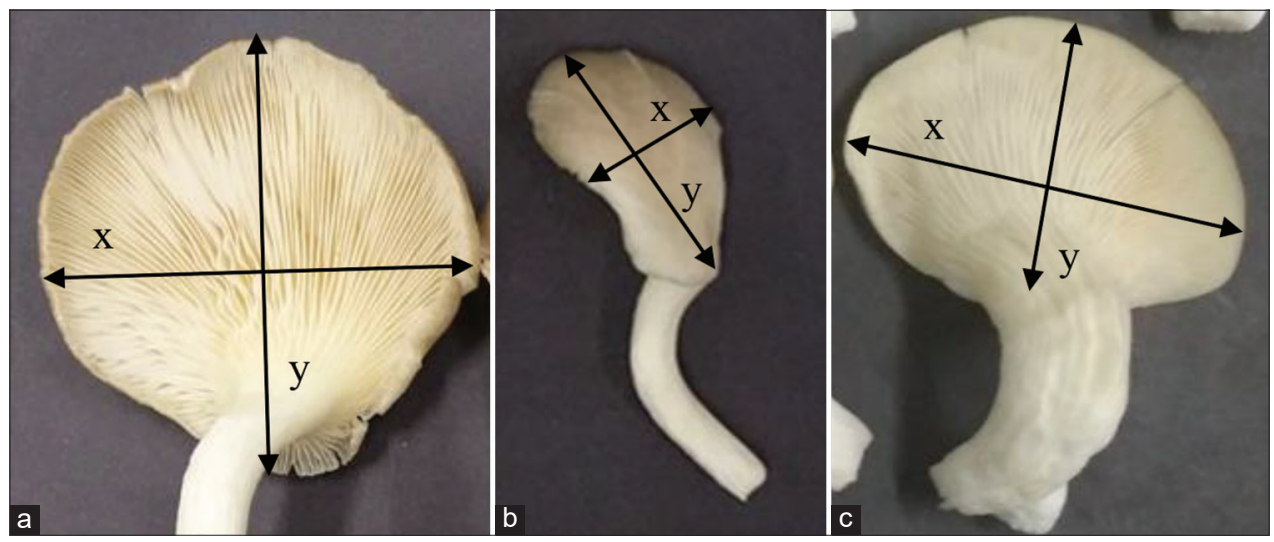

Figure 1: Three different shapes common on Pleurotus ostreatus fruiting bodies: (a) Round, (b) leaf, (c) oyster. Coordinates x and y were measured to obtain values for calculating area of fruiting body cap as an ellipse shape $(A=\pi 1 / 4 x y)$. 
is the distance across the width of the cap, which is perpendicular to $\mathrm{y}$ [Figure 1]. The BE was calculated as total mushrooms fresh weight divided by the dry weight of the substrate used per bag [15]. In this experiment, $\mathrm{BE}$ was calculated with values obtained from the first flush only because the strain 2301 IBK tested produced $80 \%$ of its total yield in the first flush [16]. The statistical analysis of the data obtained was performed using Microsoft Office Excel 2016, QI Macros 2020 software, and the Agrostat New software package [17].

\section{RESULTS AND DISCUSSION}

\subsection{Biological Efficiency}

The incubation time was $15 \pm 1$ days. The fruiting bodies in the first flush reached maturity in $5 \pm 1$ day after primordia appearance, and there were no significant differences $(P>0.05)$ among all treatments. A two-factor dispersion statistical analysis on the comparison of $\mathrm{BE}$ did not indicate differences between treatments. However, a U-test analysis for comparing averages determined that the level of BE in the horizontal position was $10 \%$ lower than the vertical and slant fruiting positions [Table 1]. The best results from the horizontal and slant positions may be because these are the positions that $P$. ostreatus fruit in nature [18]. Furthermore, the BE improved in the horizontal and vertical position with an increase in perforation size to give the highest $\mathrm{BE}$ of $77.70 \pm 6.08 \%$ and $88.04 \pm 5.74 \%$ in the horizontal and vertical position, respectively, at $150 \mathrm{~mm}$ perforation size. There was no such trend in the slant position, and the bags with $100 \mathrm{~mm}$ perforations gave the highest BE $(92.36 \pm 6.48 \%)$. These results are different from Zireva et al. [9], who reported that position on the shelf had no significant effect $(P>0.05)$ on mushroom yield.

\subsection{Cluster Characteristics}

\subsubsection{Cluster weight}

Statistical analysis (ANOVA) indicated significant differences ( $P=0.001)$ on the bag position's influence on fruiting body clusters' weight and sizes. The highest average mass $(703 \pm 86 \mathrm{~g})$ was in the horizontally positioned bags with $150 \mathrm{~mm}$ perforation and the lowest $(404 \pm 44 \mathrm{~g})$ in the vertical position with $50 \mathrm{~mm}$ perforation [Table 1]. In general, the weight of clusters obtained from $150 \mathrm{~mm}$ perforations was significantly higher $(P<0.05 ; \mathrm{LSD}=161 ; \mathrm{HSD}=257)$ than perforations of sizes 50 and $100 \mathrm{~mm}$.

\subsubsection{Cluster width and height}

The highest cluster weight ( $236 \pm 13 \mathrm{~g})$ was recorded from the bags in the horizontal fruiting position with a perforation of $150 \mathrm{~mm}$; the lowest $(186 \pm 6 \mathrm{~g})$ was from the vertical position and perforation of $50 \mathrm{~mm}$. Two-factor dispersion statistical analysis indicated that the perforation's size had a significant $(P<0.001)$ influence on the clusters' width. At the same time, the position factor is not significant $(P>0.05)$. Simultaneously, both factors had a significant $(P<0.001)$ influence on the height of clusters. Cluster height was significantly $(P<0.001)$ in the vertical and slant positions: $194 \pm 12$ and $184 \pm 10 \mathrm{~mm}$, respectively. The horizontal position gave the lowest clusters height $(122 \pm 8 \mathrm{~mm})$. Data indicated that when perforation size increased, the cluster width and height range also increased in the horizontal and vertical positions. The range in cluster width and height also increased in the horizontal and vertical positions. The dispersion of data showed significant differences $(P<0.01)$.

\subsubsection{Number of fruiting bodies per cluster}

The number of fruiting bodies in the clusters had a positive correlation ( $R^{2}=0.94$ in horizontal, 0.98 in vertical, and 0.97 in slant positions) with the increase in the size of the perforation: In any of the positions, when the perforation was $50 \mathrm{~mm}$, the average number of fruiting bodies was 25 or 26, but in the same position, when perforation was $150 \mathrm{~mm}$, there was a significant difference $(P<0.001)$, where it was $43 \pm 4$ in the vertical position, $40 \pm 3$ in vertical, and $39 \pm 4$ horizontal positions. Regression analysis of these data produced a linear equation in which we can predict the number of fruiting bodies in clusters depending on the size of the perforations used [Figure 2].

\subsection{Fruiting Bodies}

\subsubsection{Fruiting body yield and the $C W L$}

The effect of bag position and perforation size was more visible in fruiting body morphological characteristics. Individual fruiting body mass was remarkably higher in the slant position compared to the horizontal and vertical position. Substrate bags having 50 and $150 \mathrm{~mm}$ perforations in the slant position gave the highest FB yield $(21 \pm 1.2 \mathrm{~g})$; the least was in the vertical position with the same perforation sizes of 50 and $150 \mathrm{~mm}(9 \pm 0.5$ and $8 \pm 0.5 \mathrm{~g}$, respectively). The higher fruiting body mass recorded in the slant position was significantly different from the other treatments at $P<0.001$ [Figure 3].

Table 1: Biological efficiency and cluster characteristics in Pleurotus ostreatus under fruiting bag position and incision diameters treatments.

\begin{tabular}{|c|c|c|c|c|c|c|c|}
\hline \multirow[t]{2}{*}{ Variant } & \multicolumn{2}{|c|}{ Factor } & \multirow[t]{2}{*}{ Biological efficiency (\%) } & \multicolumn{4}{|c|}{ Cluster characteristic $n=25$} \\
\hline & A & B & & Mass (g) & Width (mm) & Height (mm) & FB quantity \\
\hline 1 & 1 & 1 & $73.01 \pm 6.81$ & $435^{b} \pm 51$ & $191^{\mathrm{b}} \pm 9$ & $122^{\mathrm{c}} \pm 8$ & $26^{\mathrm{bc}} \pm 3$ \\
\hline 2 & & 2 & $71.35 \pm 7.62$ & $471^{\mathrm{b}} \pm 44$ & $206^{\mathrm{b}} \pm 7$ & $138^{\mathrm{bc}} \pm 6$ & $30^{\mathrm{bc}} \pm 2$ \\
\hline 3 & & 3 & $77.70 \pm 6.08$ & $703^{a} \pm 86$ & $236^{\mathrm{a}} \pm 13$ & $157^{\mathrm{b}} \pm 11$ & $39^{\mathrm{ab}} \pm 4$ \\
\hline 4 & 2 & 1 & $77.76 \pm 3.24$ & $404^{\mathrm{b}} \pm 44$ & $186^{\mathrm{b}} \pm 6$ & $149^{\mathrm{b}} \pm 8$ & $26^{\mathrm{bc}} \pm 2$ \\
\hline 5 & & 2 & $83.71 \pm 6.53$ & $443^{b} \pm 52$ & $188^{\mathrm{b}} \pm 5$ & $158^{\mathrm{b}} \pm 8$ & $31^{\mathrm{b}} \pm 6$ \\
\hline 6 & & 3 & $88.04 \pm 5.74$ & $617^{\mathrm{ab}} \pm 76$ & $216^{\mathrm{ab}} \pm 10$ & $194^{\mathrm{a}} \pm 12$ & $43^{\mathrm{a}} \pm 4$ \\
\hline 7 & 3 & 1 & $81.68 \pm 5.18$ & $455^{\mathrm{b}} \pm 49$ & $196^{\mathrm{b}} \pm 6$ & $154^{\mathrm{b}} \pm 7$ & $25^{\mathrm{bc}} \pm 3$ \\
\hline 8 & & 2 & $92.36 \pm 6.48$ & $438^{\mathrm{b}} \pm 50$ & $191^{\mathrm{b}} \pm 8$ & $151^{\mathrm{b}} \pm 8$ & $30^{\mathrm{bc}} \pm 3$ \\
\hline 9 & & 3 & $79.81 \pm 6.81$ & $585^{\mathrm{ab}} \pm 60$ & $206^{\mathrm{b}} \pm 5$ & $184^{\mathrm{a}} \pm 10$ & $40^{\mathrm{a}} \pm 3$ \\
\hline $\mathrm{LSD}_{05}(\mathrm{~A})$ & & & 11.32 & 161 & 22 & 18 & 11 \\
\hline $\mathrm{LSD}_{05}(\mathrm{~B})$ & & & 10.58 & 157 & 19 & 12 & 12 \\
\hline
\end{tabular}

Factor A - position on the shelf: 1=Horizontal, 2=Vertical. 3=Slant; Factor B - size of perforations: 1=50 $\mathrm{mm} ; 2=100 \mathrm{~mm} ; 3=150 \mathrm{~mm}$ 


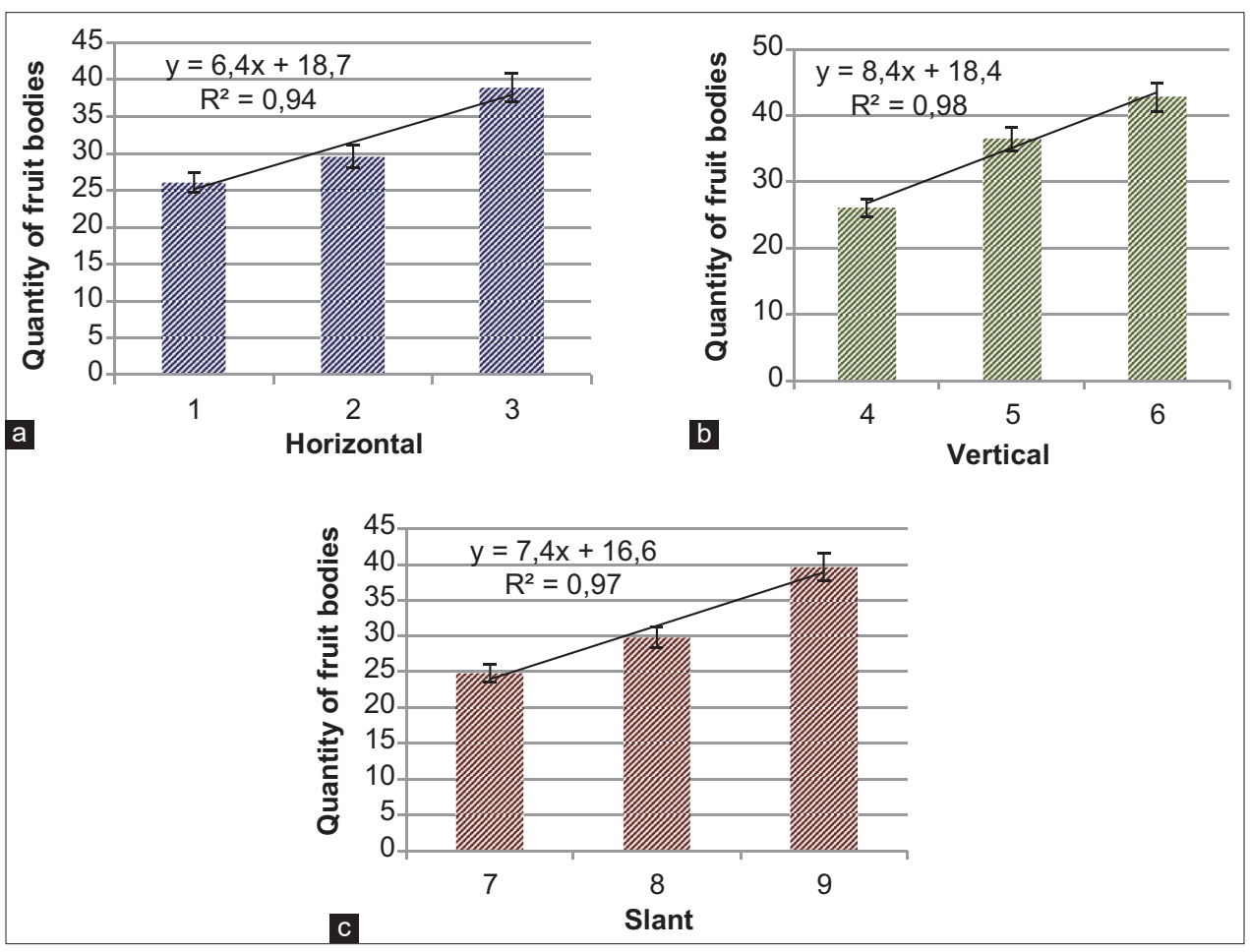

Figure 2: Effect of perforation size on quantity of fruiting bodies per cluster under the (a) horizontal position 1=50; $2=100 ; 3=150 \mathrm{~mm}$; (b) vertical position with perforation size $4=50 ; 5=100 ; 6=150 \mathrm{~mm}$; (c) slant position with perforation size $7=50 ; 8=100 ; 9=150 \mathrm{~mm}$.

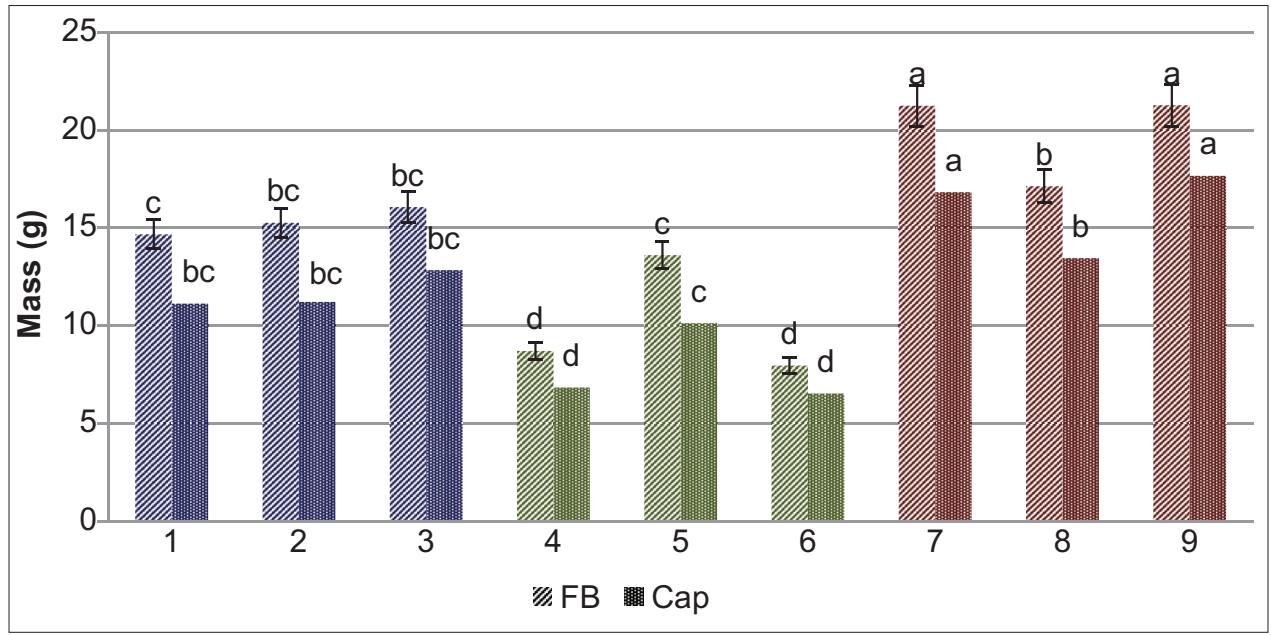

Figure 3: The average mass of FB and cap Pleurotus ostreatus horizontal 1=50; 2=100; $3=150 \mathrm{~mm}$; vertical position with perforations 4=50; 5=100; $6=150 \mathrm{~mm}$; slant position with perforations $7=50 ; 8=100 ; 9=150$.

Substantial amounts of weights are lost from total yield when caps are removed from fruiting bodies and sold as "mushroom caps-only." Fruiting body yield in the three different fruiting positions was used to calculate the CWL. Statistical analysis (ANOVA) indicated a significant difference $(P<0.05)$ in CWL. The least weight lost was with cultivation in slant $(\mathrm{CWL}=0.82)$ and vertical $(\mathrm{CWL}=0.81)$ positions in bags with $150 \mathrm{~mm}$ perforations. These CWL values were significantly different from the bags in the horizontal position, where CWL ranged between 0.75 and 0.77 for bags with 50, 100, and $150 \mathrm{~mm}$ perforations [Table 2]. A comparison of CWL and perforation size relative to cap weight indicated that the 50 and $100 \mathrm{~mm}$ perforation sizes resulted in a loss of fruiting body cap weight irrespective of the fruiting position.

\subsubsection{Size characteristics}

However, fruiting bodies produced under any fruiting position and perforation size were within the size range reported $(30-70 \mathrm{~mm}$ cap diameter) to have marketable qualities [19]. Similar results are reported for P. ostreatus strains HK-35, and another strain P-24, which has fruiting body diameters $60-100 \mathrm{~mm}$ [20]. In this experiment, in the vertical position with a $150 \mathrm{~mm}$ long perforation, smaller fruiting bodies ( $46 \pm 1.6 \mathrm{~mm}$ width and $52 \pm 1.3$ length) were recorded. Treatment 7 (slant, $50 \mathrm{~mm}$ perforations) gave the largest mushroom caps with $75 \pm 2.2 \mathrm{~mm}$ of width and $70 \pm 1.5$ of length. The least cap development in the $150 \mathrm{~mm}$ perforation under vertical position may be due to the fruiting body quantity, which was the most in this treatment, and the 
impedance to airflow around the developing fruiting bodies compared to the rest treatments. The fresh airflow into the fruiting house is usually from top to bottom, and it purges $\mathrm{CO}_{2}$ from the fruiting house. However, the fresh air movement is impeded by fruiting bodies at the top of the column leading to the formation of smaller fruiting bodies toward the middle of the column. The slightly larger fruit bodies at the bottom of the column are usually due to fresh air hitting the floor and creating a more oxygen-rich microenvironment toward the bottom of the column. However, the slant and position airflow allows better air and even air circulation around the fruiting bodies, which eventually leads to better and even cap development across the bags' fruiting surface. The market preferences for $P$. ostreatus fruiting body size and packaging differ in many countries. In Turkey, they prefer larger caps, while in Russia, they like smaller caps, mainly because they are suitable for producing pickles. Our results indicate the possibility of regulating mushroom caps to meet market preferences.

The mushroom cap area was also calculated to determine the influence of factor A (perforation size) and B (fruiting position) on yield and fruit body morphology [Figure 4]. Statistical analysis (ANOVA) indicated significant differences $(P<0.001)$ in the mushroom cap area from the slant fruiting position compared with the horizontal and vertical fruiting positions. The largest area $4368 \pm 212 \mathrm{~mm}^{2}$ was in horizontal position and $50 \mathrm{~mm}$ perforation size, followed by $4128 \pm 212 \mathrm{~mm}^{2}$ in horizontal fruiting position and $150 \mathrm{~mm}$ perforation size. The least result was $2027 \mathrm{~mm}^{2}$ in vertical fruiting position and $150 \mathrm{~mm}$ perforation size.

The characteristic, almost stemless, and shelf-like shape $P$. ostreatus earned it the name "oyster mushroom" [21]. The three common shapes encountered in this experiment and the dimensions measured to obtained data for the calculation of fruiting body area are shown in Figure 1. One-way ANOVA analysis on fruiting body asymmetry coefficient indicated statistical differences $(P<0.001)$ between treatments. The least asymmetry coefficient $(0.90 \pm 0.02)$ was obtained in the vertical position and $150 \mathrm{~mm}$ perforation size. In this treatment, clusters had the highest numbers of fruiting bodies, which could have probably affected the FB shape and area. The highest asymmetry coefficient (1.12) was found in the caps from the horizontal fruiting position and $100 \mathrm{~mm}$ perforation size. In general, wider fruiting bodies were found in the slant and horizontal than the vertical fruiting positions.

\subsubsection{Stipe length and diameter}

Stipe length depends on microclimate conditions [22]. There were significant differences $(P<0.001)$ in the stipe length of fruiting bodies from the different treatments. In the horizontal fruiting position, the larger the perforation size, the higher the stipe length. The slant position

Table 2: Morphological characteristics of Pleurotus ostreatus fruiting bodies.

\begin{tabular}{|c|c|c|c|c|c|c|c|c|}
\hline \multirow[t]{2}{*}{ Treatment } & \multicolumn{2}{|c|}{ Factor } & \multicolumn{5}{|c|}{ Fruit bodies characteristics (mean \pm SD) } & \multirow[t]{2}{*}{ Stipe diameter $(\mathbf{m m})$} \\
\hline & $\mathbf{A}$ & $\mathbf{B}$ & CWL & Cap width (mm) & Cap length (mm) & Coefficient of cap asymmetry & Stipe height (mm) & \\
\hline 1 & 1 & 1 & $0.75^{\mathrm{c}} \pm 0.01$ & $58^{\mathrm{cd}} \pm 2.4$ & $54^{\mathrm{c}} \pm 1.3$ & $1.06^{\mathrm{b}} \pm 0,02$ & $17^{\mathrm{d}} \pm 0.5$ & $16 \pm 0.7$ \\
\hline 3 & & 3 & $0.78^{\mathrm{ab}} \pm 0.02$ & $62^{\mathrm{c}} \pm 1.9$ & $61^{\mathrm{b}} \pm 1.6$ & $1.03^{\mathrm{b}} \pm 0.02$ & $26^{\mathrm{b}} \pm 1.3$ & $12 \pm 0.4$ \\
\hline 4 & 2 & 1 & $0.79^{\mathrm{ab}} \pm 0.01$ & $60^{c} \pm 1.9$ & $59^{\mathrm{b}} \pm 1.4$ & $1.03^{\mathrm{b}} \pm 0.01$ & $14^{\mathrm{f}} \pm 0.5$ & $11 \pm 0.3$ \\
\hline 5 & & 2 & $0.76^{\mathrm{bc}} \pm 0.01$ & $64^{\mathrm{bc}} \pm 2.2$ & $60^{\mathrm{b}} \pm 1.5$ & $1.06^{\mathrm{b}} \pm 0.02$ & $25^{\mathrm{bc}} \pm 1.2$ & $12 \pm 0.4$ \\
\hline 7 & 3 & 1 & $0.78^{\mathrm{ab}} \pm 0.01$ & $75^{\mathrm{a}} \pm 2.2$ & $70^{\mathrm{a}} \pm 1.5$ & $1.06^{\mathrm{ab}} \pm 0.02$ & $28^{\mathrm{a}} \pm 0.9$ & $12 \pm 0.3$ \\
\hline 8 & & 2 & $0.80^{\mathrm{ab}} \pm 0.01$ & $67^{b} \pm 2.4$ & $62^{\mathrm{b}} \pm 1.5$ & $1.08^{\mathrm{ab}} \pm 0.02$ & $22^{\mathrm{c}} \pm 1.1$ & $12 \pm 0.5$ \\
\hline 9 & & 3 & $0.82^{\mathrm{a}} \pm 0.01$ & $72^{\mathrm{ab}} \pm 2.5$ & $69^{\mathrm{a}} \pm 1.5$ & $1.03^{\mathrm{b}} \pm 0.02$ & $22^{c} \pm 0.7$ & $12 \pm 0.4$ \\
\hline $\mathrm{LSD}_{05}$ (A) & & & 0.02 & 7.9 & 6.1 & 0.06 & 4.3 & $\mathrm{P}=0.17$ \\
\hline
\end{tabular}

CWL: Weight loss coefficient, SD: Standard deviation

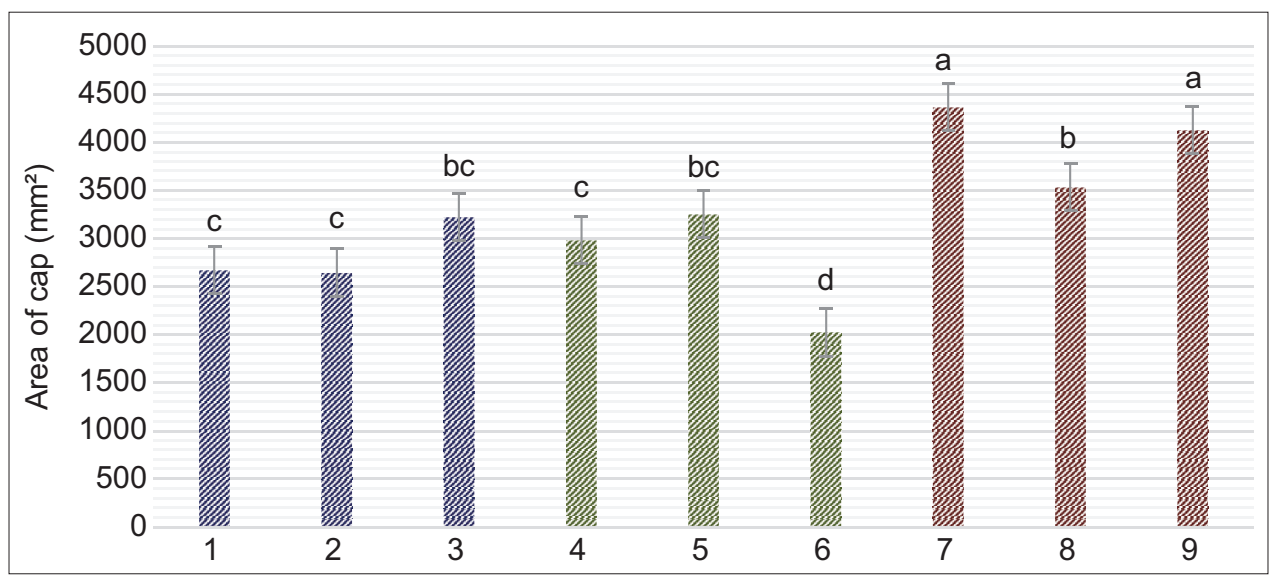

Figure 4: Aria of caps according to treatments: Horizontal position with perforations $1=50 ; 2=100 ; 3=150 \mathrm{~mm}$; vertical position with perforations $4=50 ; 5=100$; $6=150 \mathrm{~mm}$; slant position with perforations $7=50 ; 8=100 ; 9=150 \mathrm{~mm}$. 
seems the reverse because the highest length was found in the fruiting bodies from $50 \mathrm{~mm}$ perforation size. In the vertical position, $100 \mathrm{~mm}$ perforation size gave the highest stipe length, which was significantly different from 50 and $150 \mathrm{~mm}$ perforation sizes. These unexplainable observations could be the subject of further investigations. However, the long stipe is not a desirable feature in P. ostreatus fruiting bodies because it takes away from the total weight of marketable yield and reduces the cap area. There was no statistical difference $(P=0.17)$ in the stipe diameter in all treatments, which may mean that perforation sizes and fruiting position do not affect stipe diameter among all the morphological parameters monitored in this experiment.

\section{CONCLUSION}

The effect of perforation size was more on the substrate blocks in the horizontal position and linear correlation exists between perforation size and the size of mushroom fruiting body clusters. The best perforation size is $50 \mathrm{~mm}$, which can give clusters best suited for packaging and storage of oyster mushrooms in commercial operation in Ukraine. Studies of this nature on cultivated exotic mushrooms are needed for predicting cluster sizes, fruiting body morphological features, and optimum packaging requirements that reduce spoilage and food safety concerns.

\section{AUTHORSHIP}

All authors contributed to the conception, design, execution, acquisition, analysis, and interpretation of data in this study; participated in manuscript preparation and approved the final version submitted for publication. Authors agree to be accountable for all aspects of the work in ensuring that questions related to the accuracy or integrity of any part of the work are appropriately investigated and resolved.

\section{CONFLICTS OF INTEREST}

The authors declare that they have no known competing financial interests or personal relationships that could have appeared to influence the work reported.

\section{FUNDING}

There is no funding to report.

\section{PUBLISHER'S NOTE}

This journal remains neutral with regard to jurisdictional claims in published institutional affiliation.

\section{REFERENCES}

1. Kunjadia PD, Nagee A, Pandya PY, Mukhopadhyaya PN, Sanghvi GV, Dave GS. Medicinal and antimicrobial role of the oyster culinary-medicinal mushroom Pleurotus ostreatus (higher Basidiomycetes) cultivated on banana agrowastes in India. Int J Med Mushrooms 2014;16:227-38.

2. Gargano ML, Van Griensven LJ, Isikhuemhen OS, Lindequist U, Venturella G, Wasser SP, et al. Medicinal mushrooms: Valuable biological resources of high exploitation potential. Plant Biosyst 2017;151:548-65.

3. Chiu SW, Ching ML, Fong KL, Moore D. Spent oyster mushroom substrate performs better than many mushroom mycelia in removing the biocide pentachlorophenol. Mycol Res 1998;102:1553-62.

4. Koutrotsios G, Mountzouris KC, Chatzipavlidis L, Zervakis GI.
Bioconversion of lignocellulosic residues by Agrocybe cylindracea and Pleurotus ostreatus mushroom fungi--assessment of their effect on the final product and spent substrate properties. Food Chem 2014;161:127-35.

5. Priadi D, Sasliawan I. The utilization of spent oyster mushroom substrates into compost and its effect on the growth of Indian mustard (Brassica juncea (L.) Czern.) in the Screenhouse. Int J Agric Technol 2018;14:351-62.

6. Stamets P. Growing Gourmet and Medicinal Mushrooms. $3^{\text {rd }}$ ed. Berkeley, CA: Ten Speed Press; 2000. p. 574.

7. Bellettini MB, Fiorda FA, Maieves HA, Teixeira GL, Ávila S, Hornung PS, et al. Factors affecting mushroom Pleurotus spp. Saudi J Biol Sci 2019;26:633-46.

8. Okwulehie IC, Okwujiako IA. Effect of hole size and number on the fruit-body yield of Pleurotus ostreatus var. florida Eger. Dyn Biochem Process Biotechnol Mol Biol 2008;2:45-6.

9. Zireva DT, Fanadzo M, Mashingaidze AB. Effect of substrate quantity and shelf position on yield of oyster mushroom (Pleurotus sajor caju). Pak J Biol Sci 2007;10:3458-61.

10. Bisko NA, Lomberh ML, Mytropolska NY, Mykhailova OB. Collection of Mushrooms (IBK). Kyiv: Alterpress; 2016.

11. Nakasone KK, Peterson SW, Jong SC. Biodiversity of fungi. In: Preservation and Distribution of Fungal Cultures. Burlington: Academic Press; 2004. p. 37-47.

12. Bisko NA, Dudka IA. Biology and cultivation of edible oyster mushrooms. Kiev: Scientific opinion; 1987.

13. Holub HA, Abrosimova HL, Haidenko OM, Kepko OI, Tomashchuk AI. Technological Process of Substrate Production for Growing Oyster Mushrooms by Fermentation in Pasteurization Chamber. Kyiv: Naukovyi Svit; 2010.

14. Bandura II. Improvement of elements of technology of industrial production of edible mushrooms of the genus Pleurotus. $\mathrm{PhD}$ Thesis. Kyiv: National University of Life and Environmental Sciences; 2014.

15. Chang ST, Hayes WA. The Biology and Cultivation of Edible Mushrooms. New York: Academic Press; 2013.

16. Myronycheva O, Bandura I, Bisko N, Gryganskyi AP, Karlsson O. Assessment of the growth and fruiting of 19 oyster mushroom strains for indoor cultivation on lignocellulosic wastes. BioResources 2017;12:4606-26.

17. Ushkarenko VO, Vozhegova RA, Goloborodko SP, Kokovikhin SV. Statistical analysis of the results of field research in agriculture: a monograph. Kherson: Ailant; 2013.

18. Dudka IA, Bisko NA, Bilay VT. Cultivation of edible mushrooms. Kyiv: Urojay; 1992.

19. Chitamba J, Dube F, Chiota WM, Handiseni M. Evaluation of substrate productivity and market quality of oyster mushroom (Pleurotus ostreatus) grown on different substrates. Int J Agric Res 2012;7:100-6.

20. Vdovenko SA. Commercial yield of oyster mushroom at cultivation in the winterrspring period. Veg Crops Russ 2013;2:75-7. DOI: 10.18619/2072-9146-2013-2-75-77.

21. Phillips R, Reid DA. Mushrooms. London: Pan Macmillan, Mcmillan Publishers; 2006.

22. Jang KY, Jhune CS, Park JS, Cho SM, Weon HY, Cheong JC, et al. Characterization of fruitbody morphology on various environmental conditions in Pleurotus ostreatus. Mycobiology 2003;31:145-50.

How to cite this article:
Bandura I, Isikhuemhen OS, Kulik A, Serduk M, Sucharenko O, Jukova V,
Koliadenko V, Gaprindashvili N. Effect of perforation size and substrate
bag fruiting position on the morphology of fruiting bodies and clusters in
Pleurotus ostreatus (Jacq.) P. Kumm. J App Biol Biotech. 2021;9(3):35-40.
DOI: 10.7324/JABB.2021.9305

